\title{
The Course and Development Trend of China's Basic Education Curriculum Reform
}

\author{
Dan Chen ${ }^{1}$ and Changun Park ${ }^{2 *}$ \\ ${ }^{1}$ Dept. of Education, Pusan National University \\ 2, Busandaehak-ro 63, Geumjeong-gu, Busan, Korea \\ ${ }^{2}$ Dept. of Education, Pusan National University \\ 12, Busandaehak-ro 63, Geumjeong-gu, Busan, Korea \\ lamy2030@naver.com, ${ }^{2}$ cupark@pusan.ac.kr
}

\begin{abstract}
This study starts from the overall framework of the reform and development of China's basic education curriculum. This study has carried out research on the development of various reform stages, and to discuss the reform and development trends of China's basic education curriculum and the development process of the curriculum reform objectives. This study divides the development of China's basic education curriculum into four major stages and analyzes them. First, the curriculum goals and the objectives of China's curriculum reform vary and change with the development of the country and are influenced by the country's historical culture and political authorities. Second, after the founding of the country until the enactment of the Compulsory Education Law in 1986, China's basic education curriculum was completely in a transitional and experimental state that was very unstable and lacked systematic. Third, the development steps of China's basic education curriculum reform after 1982 are slow and cautious, and slowly tend to stabilize and rationalize. Although it is still in an experimental state, it can be seen that China's basic education curriculum is slowly moving closer to internationalization and scientification.
\end{abstract}

Keywords: Basic Education, Curriculum reform, Reform Course, Curriculum of China, Development Trend

\section{Introduction}

At present, there are still some shortcomings related to the reform objectives and curriculum objectives of China's basic education curriculum. The Chinese government has not yet opened a national official website for basic education courses and has not listed the educational curriculum reform documents over the years. Therefore, it is difficult to find relevant national documents. This is not only not conducive to the objective and correct research of Chinese domestic researchers, but also a research obstacle for foreign researchers. It is difficult to promote the overall objective understanding of China's basic education curriculum development framework. It is difficult for other countries in the world to objectively understand and judge the development of Chinese curriculum. So it is necessary to study the overall development framework of China's basic education curriculum reform.

About the previous research of curriculum reform, Feng Daming(2006) analyzed the development and problems of modern Chinese curriculum from 1999 to 2006. Fuquan Huang(2007) analyzed the seven goals and six strategies of the curriculum reform in 2001.

Received (May 15, 2018), Review Result (August 10, 2018), Accepted (August 20, 2018)

* Corresponding Author 
And how many curriculum reforms have been carried out in China? There is no specific statement from the Ministry of Education in China. There are not many relevant research and analysis. The curriculum reform researchers have some deviations from the segments of each period. For example, Yi Xie(2013) divides the curriculum reform in the true sense into five stages, and believes that the eight-time statement is only the preparation of eight national general textbooks, not a real reform[1]. However, Bei Wang and Zeping Peng(2015) divided the basic curriculum reform process after China's founding of the country into eight stages according to the characteristics of each time period[2]. $\mathrm{Wu}$ Changfa and Wang Qi (2016) divided the reform of China's basic education curriculum into seven stages[3].

To promote understanding of the development of China's basic education curriculum and to promote the research and development of China's basic education curriculum. this research adopts a literature research method to study and analyze the original documents of the basic education curriculum promulgated by the Chinese government and literature studies. From the perspective of the overall framework of China's basic education curriculum reform, it analyzes the purpose of curriculum reform and training purpose at various stages, and discusses the development direction and characteristics of China's basic education curriculum.

\section{Education Curriculum}

There's a little bit of difference in what each scholar says for the concept of education curriculum. Alexander and Scherer from the United States put forward the four types definitions of curriculum, that is, subject, textbook, experience, and goal. It is said that the curriculum is the planned learning opportunity. Zhong Qiquan from China thinks that the so-called curriculum is the question of what, when and how to teach in school. Park Changyan from South Korea believes that the so-called education curriculum refers to the interactive media between teachers and students in education activities, as well as the educational content learned in schools. It appears in a subject textbook in the form of a kind of conceptual writing. And with the change of times and society, the educational content in educational curriculum also transforms accordingly. In Park Changyan's book Modern Education Curriculum, the education curriculum is described in six categories, namely, the education curriculum in the education center, the education curriculum of life adjustment, the science-centered education curriculum, the education curriculum which defines the side and inner result as the center, the intensive education curriculum of basic education, and the intensive curriculum for the constitutionalism and basic education history of technical engineering[4].

Therefore, the education curriculum makes a difference to the change of various times and national societies. The education curriculum is an education curriculum programme or planning documents organized by states, regions and schools according to the form of times and social development, as well as the education curriculum content represented by the textbook as the carrier and the form of characters and pictures, which is an interactive medium for teachers and students to carry out teaching activities. While an integrated education curriculum should include a range of processes such as national programs and local school plans, textbooks and teaching activities. That is to say, the three aspects of HOW, WHEN and WHAT in the educational curriculum have been embodied, that is, how, when and how to teach.

\section{The Overview of Curriculum Reform of Basic Education in China}

By studying the documents issued by the Chinese government, it is found that the Chinese government has not clearly marked specific period of time for the curriculum reform of elementary education. Therefore, after the research and analysis, this study 
believes that the curriculum reform of elementary education in China can be divided into four stages since the founding of the People's Republic of China.

The first stage was from 1949 to 1962. The curriculum system of elementary and secondary schools in China's basic education was established. The first middle school curriculum plan was promulgated in 1950 and the first Five-year Teaching Programme in the Elementary School was issued in 1952. During this period, the whole curriculum system was mainly influenced by the Soviet curriculum, the educational experience and the traditional management model of old China, with the single curriculum provision, the lack of scientificity of class hours, no integrated curriculum, the unified teaching requirements in the whole country and the management mode of centralization. The class schedule and course description for the 1953 to 1958 teaching programme have been revised with high frequency. In addition, in order to meet the diversity in China, the country ran a school with a variety of educational systems and had the multiple educational systems of educational curriculum program[5]. During 'the Culture Revolution' period, the production labor curriculum was mainly emphasized. At that time, there was no central education department. So there are some differences in the curriculum settings across the country. For example, some schools in Beijing have only 8 weeks of culture courses throughout the year, less than $20 \%$ of the course time, and the rest time is spend on revolutionary courses and labor practice classes. This class schedule was gradually improved after 1970. In some parts of China, the time of subject curriculum was increased to $71.4 \%$, and $30 \%$ of the time in school was used for labor output[6].

The second stage was from 1963 to 1985 , when the basic education curriculum with Chinese characteristics was newly established, from the educational curriculum which advocated the combination of education and labor to the curriculum of over-emphasizing activity and practice education. This stage was the beginning of the "Great Leap Forward in Education", the "Great Famine" and the "Great Cultural Revolution" in China, which was not only a very difficult and special period, but also a period of ups and downs for Chinese education[7].

The third stage was from 1985 to 1999, which is the period of restarting the curriculum reform of elementary education in China. During this period, the Compulsory Education Law of the People's Republic of China and the Education Law of the People's Republic of China were formulated and promulgated in 1986 and 1995 respectively. With the economic development of China, the social situation tended to be stable, and the primary and secondary school educational systems had decided to adopt the parallel of 6-year-3year system and the 5-year-4-year system, while the general senior high school education had adopted the 3-year system. The stability of educational system and society greatly promoted the development of nine-year compulsory education curriculum in primary and secondary schools. In 1992, curriculum in the senior high school implement to share responsibilities for two levels, that is the national curriculum and local curriculum.

The fourth stage was from 2000 to the present, which was the trial period of promoting quality-oriented education as the core and comprehensive reform and development of elementary education, and the period of defining the 9-year compulsory education curriculum as the 6-year-3-year system and 3-year in the senior high school. The Curriculum Scheme for the Senior High School (2017 Edition), promulgated in 2018[8], aimed at cultivating the key competencies (key capabilities) of students as the center of curriculum objectives. The Ministry of Education has also issued curriculum standards for various subjects such as Chinese, and the Guidance Outline of Comprehensive Practical Curriculum in Elementary and Secondary Schools[9]. 


\title{
4. The Development Trend and Objectives of Curriculum Reform in China
}

\author{
4.1. The Purpose of Curriculum Reform and the Curriculum Objectives during the \\ Period of "new Democracy" Education and the "socialism" Educational \\ Transformation
}

The first stage (1949 to 1962), was the initial stage of curriculum system of elementary and secondary schools in China. In this stage, China's education was "New Democracy" education, and the curriculum reform of elementary education could be divided into two times. In 1950, as a result of the initial period of the founding of the People's Republic of China, the national teaching programme in the secondary school had not yet made a unified provision, and there were many differences in the curriculum programme of the secondary schools in various regions. In order to promote the teaching efficiency and realize the unified teaching in the whole country, the first interim teaching programme for secondary schools in New China had been promulgated. In 1952, the first Interim Regulations for Elementary Schools (draft) and the Interim Regulations for Secondary Schools (draft) had been also promulgated in New China. The purpose of elementary education was to cultivate students to become self-conscious and active members of the new democratic society who love their motherland and people. The task of secondary school education was to train the physical and mental development of students in an allround way so as to lay a solid foundation for their participation in the construction work in higher education. In 1957, the Notice on Secondary Educational Planing of 1957-1958 School Year was promulgated. The main purpose of this curriculum plan was to lighten the burden on students, improve the quality of teaching, and solve the problems of the burden and study quality of students.

China's education in the early days of the founding of the People's Republic of China not only followed the feudal education of authoritarian rule for thousands of years, and the education of semi-colonial and semi-feudal society education, capitalist education of Western nationalism, and also has the popular education of new democracy. According to China's $80 \%$ illiterate population and $20 \%$ enrollment rate in 1949 , the Chinese government issued a statement stating that the overall goal of the development of education in New China is to adopt the concept of a new-democratic education, improve the people's cultural level, and cultivate national talents for construction. Clearing feudal and fascism, developing the ideology of serving the people. And directly introduced the Soviet curriculum system, trying to transform the education model of the old society and create a new curriculum system.

The second stage (1963-1977), was the initial stage of basic education curriculum with Chinese characteristics. From the late 1950s to 1963, China's education gradually changed from "New Democracy" education to "Socialism" education. In 1963, The Notice on the Implementation of the New Teaching Programme for Full-time Elementary and Secondary Schools (draft) was promulgated, which established the curriculum model with emphasis on "basic knowledge" and "basic skill training". The programme indicated that the fundamental objective of elementary and secondary school education was to cultivate tough revolutionary offspring. The main task of cultural education was to equip students with basic cultural tools and scientific knowledge. The Notice on the Adjustment and Simplification of Elementary and Secondary School Curriculum in 1964 showed that in order to lighten the course load of elementary and secondary school students, improve the quality of teaching and make students develop in an all-round way, it is necessary to reform the subjects of curriculum in elementary and secondary schools. Since then, the teaching programme of 1963 had not been implemented. During the "Great Cultural Revolution" from 1966 to 1976, school activities and curriculum teaching in the whole country had been force to stagnate from 1966 to 1968. Schools began to resume classes in 
1969, but due to the lack of a unified administrative department for education, the curriculum in various regions were organized locally. Almost all the educational contents and activities was taking the "Great Cultural Revolution" as the theme so as to cultivate and facilitate the revolutionary spirit as the educational objective.

The second curriculum reform phase is the beginning of the period of building socialism, and the main reason for the curriculum reform is that the social problems arising from the growing demand for material culture and backward social production are increasingly prominent. in order to improve this problem, the Chinese government at that time decided to promote education reform and establish a basic education curriculum system with Chinese characteristics. Therefore, the Chinese government has set a new educational goal of education for the proletariat and education combined with productive labor. The curriculum of the Cultural Revolution period, from a combination of education and productive labor becomes a major emphasis on productive labor, the proportion of teachers and students is seriously uneven, there are even 12 teachers with 200 students. The proportion of cultural classes and production labor classes is seriously uncoordinated. Students spend most of their time working in factories or farms of school. Such an education model not only creates a chaotic situation for society and schools, but also is detrimental to students' academic development and physical growth. However, the labor and manufacturing output and contribution of the school and students during this period cannot be ignored.

\subsection{The Purpose of Curriculum Reform and the Curriculum Objective after the Restart of Curriculum Reform}

The third stage (1977 to 1999), was the restart period of curriculum reform of elementary education in China, which was the end of the "Great Cultural Revolution" in China and the restart period of curriculum reform of elementary education. In 1977, with the combination of experience of the "Great Cultural Revolution" and curriculum reform of international elementary and secondary school, the modernization reform of curriculum was carried out. The ten-year teaching programme for elementary and secondary schools in 1978 made clear that the programme was promulgated for the purpose of correct educational revolution, improving teaching quality, establishing a proletarian educational system suitable for China's national condition and socialist economic foundation. The teaching objectives of elementary and secondary schools were to train students to lay a good foundation of moral education, intellectual education and physical education, so as to cultivate reserve forces of qualified labor for the country and to train qualified new students for higher schools, so that students could learn the basic knowledge of advanced culture and science, gradually had the ability of self-study, analysis and solving problems, and had certain knowledge and function for industrial and agricultural production.

In 1988, the first compulsory education teaching programme was issued after the Compulsory Education Law was promulgated. The training objective of primary and secondary schools was to cultivate students with the love for motherland and labor, and cultivate students' good habits of life behavior and healthy body, with the essential ability and the ability of discerning right from wrong. In 1990, the purpose of the curriculum reform for general senior high school education was to solve the problems of the general senior high school in which the subject of arts and science tended to go overboard, the proportion of knowledge structure was unreasonable, and the burden of school work was too heavy, to pay attention to the development of students' interest and specialty, to improve the students' quality and to enhance their ability to adapt to social life and production. The purpose of the curriculum reform for compulsory education in 1992 was to carry out the educational policy, to insist on the service of education for socialist construction and to combine education with productive labor. Its training objective was about the same as the teaching programme in 1988. In 1996, the first curriculum 
programme for senior high school connected with compulsory education was issued, and its training objective had not changed greatly.

The fourth stage (2000 to the present). The objectives of the compulsory education curriculum in 2001 and the general senior high school curriculum in 2003 were to train students to form the correct three contemplations, with innovative spirit, practical ability, scientific and humanistic literacy, environmental awareness, and basic knowledge skills and methods for lifelong learning. In 2001, education mainly advanced quality-oriented education. The core objective of the general senior high school curriculum in 2017 was to cultivate the core competency of subjects for students.

The fourth phase of the education curriculum reform is mainly divided into nine-year compulsory education curriculum and ordinary high school curriculum. The main curriculum objectives are openness, democracy, science and priority development, education-oriented, reform and innovation, promotion of fairness and improvement of quality.

The goal of High school curriculum is to train students life-long learning and scientific and cultural capabilities, independent development ability, the correct ideals and beliefs and so on. Although the curriculum and description of the formal high school curriculum is more complete than the transitional adjustment program, there are still many explanations and the whole system is not perfect. For example, although the school curriculum was included in the curriculum, the school curriculum concept or other related matters were not explained. the 2017 high school curriculum added optional compulsory courses, but did not explain the meaning and purpose of the optional compulsory courses and so on.

\section{Conclusions}

This study divides China's basic education curriculum into four stages, and analyzes the purpose of curriculum reform and the purpose of curriculum training in China according to the four major stages. The conclusions are as follows.

Firstly, according to the above content, the reform goal of China's first curriculum reform stage is mainly to unify the national curriculum and conduct unified management after the founding of the country. The purpose of the course is to improve teaching efficiency, improve the quality of education, solve students' learning burden, and improve students' physical health problems.

The second curriculum reform stage mainly include the socialist education building and the eradication of illiteracy, the promotion of basic knowledge education throughout the country, and the improvement of national creativity. The purpose of the course is to cultivate students' basic cultural level, labor spirit and labor habits. Although cultivating students' labor ability is the main educational goal, but improving national output is the real goal. Although such output result seems to contribute to the country's economic development, the facts prove that it is not conducive to education development.

The third curriculum reform period, the main purpose of the reform is to realize the new educational concept of education modernization, globalization and future. And aimed at cultivating students' moral, intellectual, and artistic development, and developing objective judgments. Middle school students receive vocational and employment guidance to promote employment. The goal of the curriculum from the late 1990s to the 2000s was mainly on quality education, and began to pay attention to students' selflearning ability and ability to collect intelligence and solve problems. During the 1990s, China's development in all aspects was basically stable, and economic development showed a good phenomenon. For China's further development, cultivating students' basic ability to adapt to modern development is the main course objective at this stage.

The fourth curriculum reform stage in the 2000s, the fourth curriculum reform stage also focused on quality education. The training of vocational skills in the third reform 
stage slowly faded out of sight, and instead emphasized the cultivation of students' comprehensive quality and self-study ability, lifelong learning ability, and innovative spirit are the training objectives. By 2017, the high school curriculum advocates the cultivation of students' core competence. From this point, it can be seen that the curriculum objective of fourth curriculum reform began have become more long-term. Compared with the objective of cultivating students' employment in the third curriculum reform, the fourth curriculum reform is more inclined to train students in the direction of higher studies.

It can be seen that the purpose of the curriculum will change with the development of the times and the country, and it will also be influenced by the historical and cultural background of the country, and will present a different state. Although, from the perspective of Chinese curriculum, it seems that it is slowly becoming internationalized, but in actual operations, more time and financial support is needed to enable it to be realized.

Secondly, the first curriculum plan after the founding of the People's Republic of China was the first secondary school teaching programme, which was developed for the purpose of unified curriculum regulation and management of the postwar founding of the People's Republic of China. From the founding of the People's Republic of China to 1963, the basic education curriculum in China was influenced by the Soviet curriculum, with a single curriculum provision, the unreasonable allocation of course hours, and the lack of integrated curriculum. After 1963, China began to set up curriculum with Chinese characteristics, emphasizing the educational concept of combining teaching with labor, and the study of basic knowledge and basic skills, especially the knowledge of production technology related to agriculture, which was very in line with the needs of Chinese national conditions at that time. From 1966 to 1977, Chinese education was in a low state. after the Compulsory Education Law of was formulated and promulgated in 1986, the basic education curriculum was divided into nine-year compulsory education curriculum and general senior high school curriculum. Until 2017, the trial period of basic education curriculum experienced more than ten years. Therefore, we could see that the promotion steps of basic education curriculum development in China were slow and cautious.

Third, the "Great Cultural Revolution", which was directly induced by the educational reform, brought the development of Chinese education to a standstill for more than a decade. If we took the period of the "Great Cultural Revolution" as the central axis to explain the characteristics of the curriculum reform of elementary education in China, in the process of the curriculum reform of elementary education before the "Great Cultural Revolution" broke out in 1966, the change frequency of the contents and instructions of educational system and course was larger. During the period from 1950 to 1962, the education program was updated on average once a year, especially in the period of "the Great Leap Forward in Education", and the basic education curriculum was completely in a very unstable and transitional state with lack of systematicness. After the end of the "Great Cultural Revolution" in 1976, with the experience of the Great Cultural Revolution, the curriculum reform of elementary education in China became more stable and prudent. Until 2000, the trial implementation of curriculum reform of elementary education in China was basically realized, and the speed of revision slowed down. The curriculum reform gradually tended to stabilize, and gradually moved towards rationalization, scientization and internationalization. From this point, we could see that the basic education curriculum in China is developing towards openness and scientificity.

\section{References}

[1] Y. Xie, Y. Ma and Z. Zhang, "Is it Ture that the Curriculum Reform has been Really Carried Out for Eight Times in New China", Educational Research, vol. 397, no. 2, (2013), pp. 125-146.

[2] B. Wang and Z. Peng, "60 Years' Basic Education Curriculum Reform of New China: History and Experience”, Education and Teaching Research, vol. 29, no. 10, (2015), pp. 26-86. 
[3] C. Wu, Q. Wang and B. Li, "The Course and Trend of Basic Education Curriculum Reform in the People's Republic of China", Curriculum, Teaching Material and Method, vol. 36, no. 5, (2016), pp. 2935.

[4] C. Park, "Introduction of Curriculum Studies", Hakjisa Press, (2017), pp. 63-81.

[5] J. Zhang, "History of Basic Education Curriculum", People's Education Press, (2011), pp. 117-169.

[6] Q. Zhou, "Education Revolution in Great Cultural Revolution", Guangdong Education press, (1999), pp. 138-140.

[7] Q. Zhou, "Educational Revolution in the Cultural Revolution", Guangdong Education Publishing House, (1999), pp. 80-90.

[8] Ministry of Education of People's Republic, “Ordinary High School Curriculum Programme”, People's Education Press, (2017), pp. 1-16.

[9] http://www.gov.cn/xinwen/2017-10/30/content_5235316.htm (2017). 